\title{
Combination of modified carbapenem inactivation method (mCIM) and EDTA-CIM (eCIM) for phenotypic detection of carbapenemase-producing Enterobacteriaceae
}

\author{
Ya-Min Tsai ${ }^{1+}$, Shining Wang ${ }^{2+}$, Hui-Chuan Chiu', Cheng-Yen Kao ${ }^{2 *+}$ (1) and Li-Li Wen ${ }^{1 *+}$
}

\begin{abstract}
Background: Carbapenemase-resistant Enterobacteriaceae (CRE) cause many serious infections resulting in increasing treatment cost, prolonged hospitalization, and mortality rate. Reduced expression and/or mutations of porins and the presence of carbapenemase promote Enterobacteriaceae survival under carbapenem treatments. Development of accurate methods for the detection of antimicrobial resistance is required not only for therapy but also to monitor the spread of resistant bacteria or resistance genes throughout the hospital and community. In this study, we aimed to evaluate the phenotypic methods, Modified Hodge test (MHT), modified carbapenem inactivation method (mCIM), and EDTA-CIM (eCIM) for the detection of carbapenemase-producing Enterobacteriaceae (CPE).

Results: The results showed that $\mathrm{mCIM}$ had a sensitivity of $100 \%$ and a specificity of 100\%, whereas the MHT had a sensitivity of $84.8 \%$ and a specificity of $97.8 \%$ for the 195 CRE isolates tested (105 CPE and 90 non-CPE isolates). The sensitivity of the $\mathrm{mCIM} / \mathrm{eCIM}$ to detect metallo-carbapenemases in this study was $89.3 \%$ and the specificity was $98.7 \%$ as compared to the genotypic PCR detection.
\end{abstract}

Conclusions: These findings indicate that the mCIM combined with eCIM is useful for detecting and distinguishing different types of carbapenemase in Enterobacteriaceae.

Keywords: Carbapenemase, Enterobacteriaceae, eCIM, mCIM, Phenotypic detection

\footnotetext{
*Correspondence: kaocy@ym.edu.tw; eckwen@yahoo.com

${ }^{\dagger}$ Ya-Min Tsai and Shining Wang contributed equally to this article.

${ }^{+} \mathrm{Li}$-Li Wen and Cheng-Yen Kao contributed equally to this article.

${ }^{2}$ Institute of Microbiology and Immunology, School of Life Science, National

Yang-Ming University, No.155, Sec.2, Linong Street, Taipei 112, Taiwan

'Department of Clinical Laboratory, En Chu Kong Hospital, No. 399, Fuxing

Rd., Sanxia Dist, New Taipei City 23702, Taiwan
}

(c) The Author(s). 2020 Open Access This article is licensed under a Creative Commons Attribution 4.0 International License, which permits use, sharing, adaptation, distribution and reproduction in any medium or format, as long as you give appropriate credit to the original author(s) and the source, provide a link to the Creative Commons licence, and indicate if changes were made. The images or other third party material in this article are included in the article's Creative Commons licence, unless indicated otherwise in a credit line to the material. If material is not included in the article's Creative Commons licence and your intended use is not permitted by statutory regulation or exceeds the permitted use, you will need to obtain permission directly from the copyright holder. To view a copy of this licence, visit http://creativecommons.org/licenses/by/4.0/ The Creative Commons Public Domain Dedication waiver (http://creativecommons.org/publicdomain/zero/1.0/) applies to the data made available in this article, unless otherwise stated in a credit line to the data. 


\section{Background}

Enterobacteriaceae are Gram-negative, facultatively anaerobic, non-spore-forming rods and one of the most prevalent causes of invasive infections and nosocomial infections [1]. Infections caused by Enterobacteriaceae are often difficult to treat due to the high antimicrobial resistance among clinical isolates [2]. Carbapenems (imipenem, ertapenem, meropenem, and doripenem) are considered as "antibiotics of last-resort" in the treatment of critically ill patients with a variety of bacterial infections due to their broad spectrum among $\beta$-lactam antibiotics and relative resistance to hydrolysis by most $\beta$-lactamases [3, 4]. However, carbapenem-resistant Enterobacteriaceae (CRE) have emerged and become a public health threat worldwide in the past decade [5].

While carbapenems enter bacterial cells via specific porins, the reduced expression and/or mutation of porins plays a critical role in the resistance to carbapenems $[6,7]$. Moreover, the presence of carbapenemase genes on conjugative plasmids for the hydrolysis of carbapenems to promote Enterobacteriaceae survival under antibiotic treatments is associated with the rapid emergence of CRE [8]. $\beta$-lactamases are categorized according to sequence homology into four molecular classes: A, B, C and $D$ [9], whereas carbapenemases are the members of class A, B, and D $\beta$-lactamases [10]. Moreover, based on the participation of divalent cations in enzyme activation, carbapenemases are segregated into non-metallo- $\beta$ lactamases (zinc-independent serine carbapenemases, classes A and D) and metallo- $\beta$-lactamases (MBLs, zincdependent, class B) [11]. Therefore, EDTA or dipicolinic acid can serve as chelators to block class B carbapenemases activity by binding zinc [12]. MBL genes such as $b l a_{\mathrm{NDM}}, b l a_{\mathrm{IMP}}, b l a_{\mathrm{VIM}}$, and non-metallo-carbapenemase genes, bla $a_{\mathrm{OXA}}$ (class D) and $b l a_{\mathrm{KPC}}$ (class A), have been frequently reported in CRE, called carbapenemaseproducing Enterobacteriaceae (CPE) [8, 13-15].

The characterization of underlying mechanisms leading to carbapenem resistance of clinical isolates is not undertaken by most clinical microbiology laboratories for therapeutic decision-making; however, understanding if an isolate is CPE has significant epidemiological implications for monitoring local epidemiology and also lead to more effective treatment of infections caused by CPE (e.g. ceftazidime-avibactam or meropenem-vaborbactam, which have activity against KPC-producer) [16].

The Modified Hodge test (MHT) is the first Clinical \& Laboratory Standards Institute (CLSI) recommended growth-based carbapenemase detection test in 2009 with high level of sensitivity and specificity in detecting carbapenemases $[17,18]$. Currently, the modified carbapenem inactivation method (mCIM) has been reported to accurately identify carbapenemases but cannot distinguish between serine and metallo-carbapenemases [19, 20].
Therefore, a further modification to mCIM with the addition of EDTA (eCIM) has been endorsed in the CLSI M100-S28 supplement in 2018 to specifically identify metallo-carbapenemases $[19,20]$. In this study, we aimed to evaluate the phenotypic detection methods MHT, mCIM, and eCIM for detecting CPE.

\section{Results}

\section{Detection of carbapenemase genes by PCR}

To detect the presence of carbapenemase genes among our 419 CRE isolates, we performed PCR on 7 Citrobacter koseri, 8 Klebsiella aerogenes, 21 Enterobacter cloacae, 73 E. coli, and 310 Klebsiella pneumoniae isolates. The PCR results showed that 105 (25.1\%, 105/419) CRE isolates were genetically characterized to carry carbapenemase genes: bla $a_{\text {OXA-48 }}$ was detected in 41 (39.0\%) isolates, $b l a_{\mathrm{KPC}}$ was detected in $34(32.4 \%)$ isolates, bla $a_{\mathrm{NDM}}$ in $15(14.3 \%)$ isolates, bla $a_{\mathrm{IMP}}$ in $7(6.7 \%)$ isolates, and bla $a_{\mathrm{VIM}}$ in $3(2.9 \%)$ isolates. Five isolates carried two types of carbapenemase genes $\left(b l a_{\mathrm{NDM}}\right.$ and $b l a_{\mathrm{OXA}-48}$ in three E. coli isolates, and bla $a_{\mathrm{KPC}}$ and bla $a_{\mathrm{OXA}-48}$ in $2 \mathrm{~K}$. pneumoniae isolates).

\section{Phenotypic detection of carbapenemase-producing Enterobacteriaceae}

The ability of CRE isolates to produce carbapenemases was tested by MHT first. Ninety non-carbapenemase-producing CRE isolates were randomly selected as negative controls. Out of the 195 isolates (105 CPE and 90 non-CPE), 91 were MHT-positive for carbapenemase production (2 falsepositive isolates) (Table 1). Moreover, 16 isolates showed false-negative MHT results (Table 1). MHT had excellent sensitivity for the detection of $b l a_{\mathrm{OXA}-48}(95.1 \%)$ and $b l a_{\mathrm{KPC}}$ (100\%), but not bla $a_{\mathrm{NDM}}(46.7 \%), b l a_{\mathrm{IMP}}(57.1 \%)$, and $b l a_{\mathrm{VIM}}$ (33.3\%) (Table 1). The overall sensitivity and specificity of MHT in this study for the detection of CPE was 84.8 and $97.8 \%$, respectively (Table 1 ).

The $\mathrm{mCIM}$ and eCIM procedures and interpretation are shown in Fig. 1a. All CPE isolates and 90 non-CPE isolates were used to evaluate the $\mathrm{mCIM}$ and $\mathrm{mCIM}$ combined with eCIM (mCIM/eCIM) to detect carbapenemase producers. The interpretation of $\mathrm{mCIM}$ and eCIM results of clinical isolates were shown in Fig. 1b. Isolate 459 was a noncarbapenemase producer and isolates 448 (bla $a_{\text {OXA-48 }}$ positive) and 451 ( $b l a_{\mathrm{KPC}-2}$ positive) were serine-carbapenemase producers (Fig. 1b). In contrast, isolate 429 expressed a metallo-carbapenemase ( $b l a_{\mathrm{NDM}-5}$ positive) and thus served as $\mathrm{mCIM} / \mathrm{eCIM}$ positive control (Fig. 1b).

\section{Sensitivity and specificity of $\mathrm{mCIM}$ and eCIM for the detection of CPE}

The distribution of carbapenemase genes and results of phenotypic detection of carbapenemases in our CRE isolates were shown in Table 2. The MHT, mCIM, and 
Table 1 Sensitivity and specificity of Modified Hodge test for the detection of carbapenemase-producing Enterobacteriaceae

\begin{tabular}{|c|c|c|c|c|c|c|c|c|c|}
\hline & OXA-48 & KPC & NDM & IMP & VIM & NDM/OXA-48 & KPC/OXA-48 & carbapenemase (-) & total \\
\hline $\mathrm{TP}(\mathrm{n})$ & 39 & 34 & 7 & 4 & 1 & 2 & 2 & - & 89 \\
\hline $\mathrm{FN}(\mathrm{n})$ & 2 & 0 & 8 & 3 & 2 & 1 & 0 & - & 16 \\
\hline $\mathrm{TN}(\mathrm{n})$ & - & - & - & - & - & - & - & 88 & 88 \\
\hline $\mathrm{FP}(\mathrm{n})$ & - & - & - & - & - & - & - & 2 & 2 \\
\hline Sensitivity (\%) & 95.1 & 100 & 46.7 & 57.1 & 33.3 & 66.7 & 100 & - & 84.8 \\
\hline Specificity $(\%)^{\mathrm{b}}$ & - & - & - & - & - & - & - & 97.8 & 97.8 \\
\hline
\end{tabular}

${ }^{\mathrm{a}}$ Sensitivity $=\mathrm{TP} / \mathrm{TP}+\mathrm{FN}$

${ }^{\mathrm{b}}$ Specificity $=$ TN/TN + FP

$T P$ true positive, $F N$ false negative, $T N$ true negative, $F P$ false positive

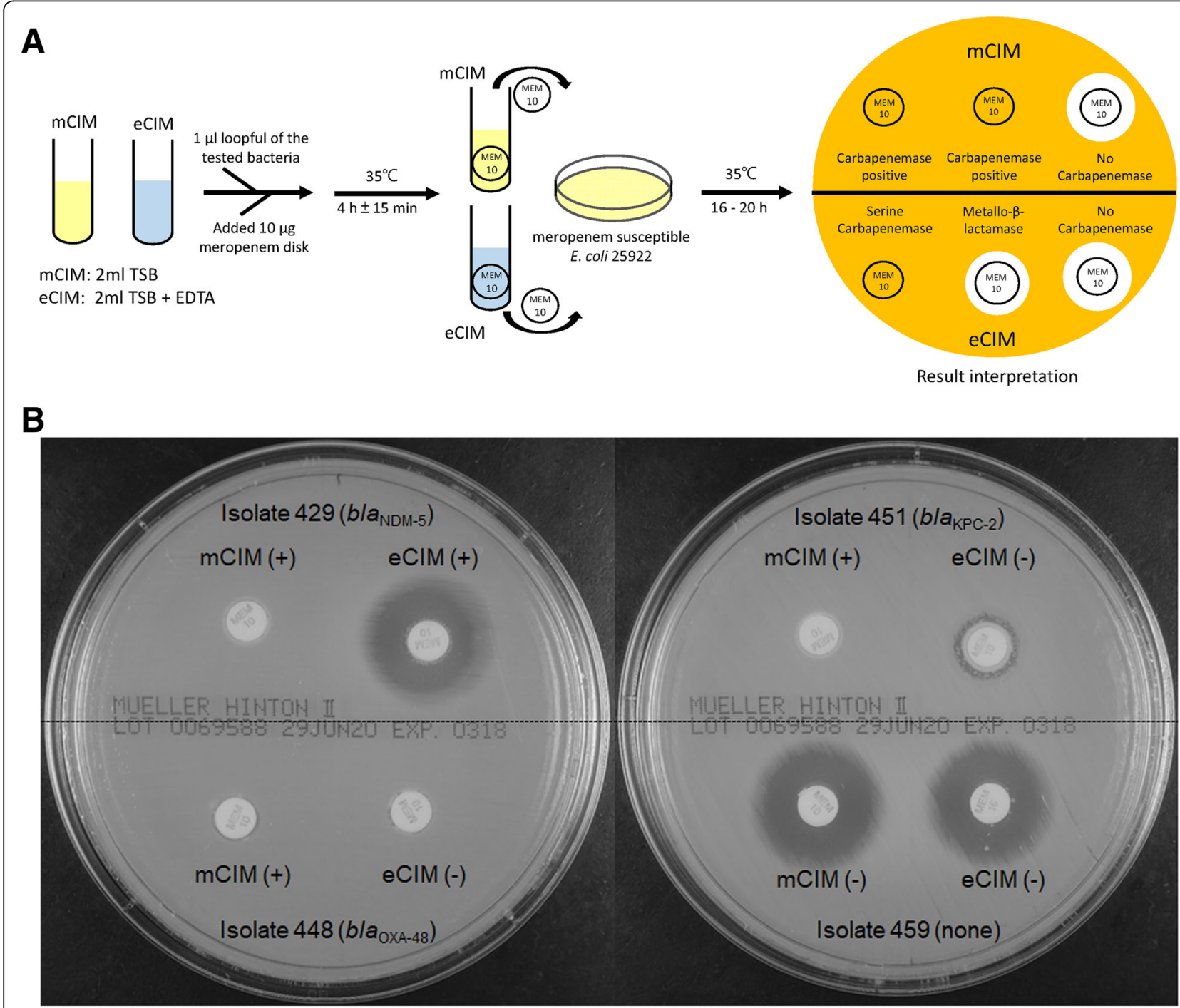

Fig. 1 The procedure and interpretation of $\mathrm{mCIM}$ and eCIM. a. A 1- $\mu \mathrm{L}$ loopful of test CRE isolate is resuspended in two tubes containing $2 \mathrm{~mL}$ of TSB. One tube is devoid of EDTA (mCIM), while the other is supplemented with EDTA (eCIM). A meropenem (MEM) disk is submerged in each tube, and the tubes are incubated at $35^{\circ} \mathrm{C}$ for $4 \mathrm{~h} \pm 15 \mathrm{~min}$. The disks are then removed from the tubes and placed on $\mathrm{MH}$ agar plates upon which a carbapenem-susceptible reporter E. coli ATCC 25922 has been freshly applied. The plates are incubated at $35^{\circ} \mathrm{C}$ for 16 to $20 \mathrm{~h}$ before the zone sizes are recorded. $\mathbf{b}$. Interpretation of $\mathrm{mCIM}$ and eCIM tests of 4 clinical $K$. pneumoniae isolates. Isolate 459 was carbapenemase negative; 429 had metallo- $\beta$-lactamase $\left(b / a_{\text {NDM-5 }}\right) ; 448$ had serine carbapenemase $\left(b / a_{\mathrm{OXA}-48}\right) ; 451$ had serine carbapenemase $\left(b / a_{\mathrm{KPC}-2}\right)$ 
Table 2 Carbapenemase genes, MHT, mCIM, eCIM, and antibiotic susceptibility of 195 CRE isolates

\begin{tabular}{|c|c|c|c|c|c|c|c|c|c|c|c|c|}
\hline \multirow[t]{2}{*}{ Species } & \multirow{2}{*}{$\begin{array}{l}\text { Carbapenemase- } \\
\text { encoding genes }^{a}\end{array}$} & \multirow{2}{*}{$\begin{array}{l}\text { No. of } \\
\text { strains }\end{array}$} & \multicolumn{2}{|c|}{ MHT (n) } & \multicolumn{2}{|c|}{ mCIM (n) } & \multicolumn{2}{|c|}{ eCIM (n) } & \multicolumn{4}{|c|}{ Carbapenem resistance $(n)^{b}$} \\
\hline & & & Neg & Pos & Neg & Pos & Neg & Pos & IPM & ETP & MEM & DOP \\
\hline \multirow[t]{2}{*}{ Citrobacter koseri } & $b / a_{\mathrm{OXA}-48}$ & 4 & 0 & 4 & 0 & 4 & 4 & 0 & 4 & 4 & 4 & 4 \\
\hline & None & 3 & 3 & 0 & 3 & 0 & ND & ND & 2 & 3 & 2 & 2 \\
\hline \multirow[t]{3}{*}{ Enterobacter cloacae } & $b l a_{I M P}$ & 2 & 1 & 1 & 0 & 2 & 0 & 2 & 2 & 2 & 2 & 2 \\
\hline & $b / a_{\mathrm{OXA}-48}$ & 1 & 0 & 1 & 0 & 1 & 1 & 0 & 0 & 1 & 1 & 0 \\
\hline & None & 9 & 9 & 0 & 9 & 0 & ND & ND & 4 & 9 & 2 & 3 \\
\hline \multirow[t]{5}{*}{ Escherichia coli } & $b^{b} a_{\mathrm{KPC}}$ & 5 & 0 & 5 & 0 & 5 & 5 & 0 & 5 & 5 & 5 & 5 \\
\hline & $b / a_{\mathrm{NDM}}$ & 11 & 6 & 5 & 0 & 11 & 0 & 11 & 11 & 11 & 11 & 11 \\
\hline & $b / a_{\text {OXA-48 }}$ & 13 & 1 & 12 & 0 & 13 & 12 & 1 & 10 & 13 & 10 & 11 \\
\hline & $b / a_{\text {NDM }} / b / a_{O X A-48}$ & 3 & 1 & 2 & 0 & 3 & 2 & 1 & 3 & 3 & 3 & 3 \\
\hline & None & 18 & 18 & 0 & 18 & 0 & ND & ND & 10 & 16 & 6 & 5 \\
\hline \multirow[t]{3}{*}{ Klebsiella aerogenes } & bla & 1 & 1 & 0 & 0 & 1 & 0 & 1 & 1 & 1 & 1 & 1 \\
\hline & $b l a_{N D M}$ & 1 & 0 & 1 & 0 & 1 & 0 & 1 & 1 & 1 & 1 & 1 \\
\hline & None & 6 & 5 & 1 & 6 & 0 & ND & ND & 5 & 6 & 3 & 2 \\
\hline \multirow[t]{7}{*}{ Klebsiella pneumoniae } & $b^{b} a_{K P C}$ & 29 & 0 & 29 & 0 & 29 & 29 & 0 & 29 & 29 & 29 & 29 \\
\hline & $b l a_{1 \mathrm{MP}}$ & 5 & 2 & 3 & 0 & 5 & 1 & 4 & 5 & 5 & 4 & 4 \\
\hline & bla & 2 & 1 & 1 & 0 & 2 & 0 & 2 & 2 & 2 & 2 & 2 \\
\hline & $b l a_{N D M}$ & 3 & 2 & 1 & 0 & 3 & 0 & 3 & 3 & 3 & 3 & 3 \\
\hline & $b / a_{\mathrm{OXA}-48}$ & 23 & 1 & 22 & 0 & $23^{c}$ & 23 & 0 & 22 & 23 & 22 & 21 \\
\hline & $b / a_{\mathrm{KPC}} / b / a_{\mathrm{OXA}-48}$ & 2 & 0 & 2 & 0 & 2 & 2 & 0 & 2 & 2 & 2 & 2 \\
\hline & None & 54 & 53 & 1 & 54 & 0 & ND & ND & 28 & 54 & 25 & 23 \\
\hline Total & & 195 & 10 & 91 & 90 & 105 & 79 & 26 & 149 & 193 & 138 & 134 \\
\hline
\end{tabular}

${ }^{a}$ Class A carbapenemase, KPC; Class B carbapenemase, IMP, NDM, and VIM; Class D carbapenemase, OXA-48

${ }^{\mathrm{b}}$ Antibiotic susceptibility to carbapenems was determined by disc diffusion. IPM, imipenem; ETP, ertapenem; MEM, meropenem; DOP, doripenem

"The results of $2 \mathrm{mCIM}$ tests were interpreted as "indeterminate" (pinpoint colonies were present within a 16- to 18-mm zone)

Pos positive, Neg negative

eCIM tests were replicated by two independent investigators to ensure reproducibility, and the results showed full reproducibility of these tests. Importantly, two isolates ( $1 \mathrm{~K}$. pneumoniae and $1 \mathrm{~K}$. aerogenes) with a falsepositive result on MHT showed a negative result on mCIM. Moreover, 16 isolates with a false-negative result on MHT were mCIM positive (Table 2). The sensitivity and specificity for the mCIM to detect carbapenemase were both $100 \%$ in this study.

The sensitivity for the mCIM combined with eCIM to detect different classes of carbapenemases was shown in Table 3. Twenty-five metallo-carbapenemase producers showed positive results by eCIM. However, a total of 3 isolates escaped the detection of metallo-carbapenemase,

Table 3 Sensitivity and specificity for the mCIM combined with eCIM to detect different types of carbapenemase

\begin{tabular}{|c|c|c|c|c|c|c|c|c|}
\hline $\mathrm{mCIM}+\mathrm{eCIM}$ & $b l a_{\mathrm{OXA}-48}$ & $b l a_{\mathrm{KPC}}$ & $b l a_{\mathrm{NDM}}$ & $b / a_{\mathrm{IMP}}$ & $b l a_{\mathrm{VIM}}$ & $b l a_{\mathrm{NDM}} / b / a_{\mathrm{OXA}-48}{ }^{d}$ & $b l a_{\mathrm{KPC}} / b l a_{\mathrm{OXA}-48}$ & total \\
\hline $\mathrm{TP}(\mathrm{n})$ & - & - & 15 & 6 & 3 & 1 & - & 25 \\
\hline $\mathrm{FN}(\mathrm{n})$ & - & - & 0 & 1 & 0 & 2 & - & 3 \\
\hline TN (n) & $40^{c}$ & 34 & - & - & - & - & 2 & 76 \\
\hline $\mathrm{FP}(\mathrm{n})$ & 1 & 0 & - & - & - & - & 0 & 1 \\
\hline Sensitivity (\%) & - & - & 100 & 85.7 & 100 & 33.3 & - & 89.3 \\
\hline Specificity $(\%)^{\mathrm{b}}$ & 97.6 & 100 & - & - & - & - & 100 & 98.7 \\
\hline
\end{tabular}

${ }^{\mathrm{a}}$ Sensitivity $=\mathrm{TP} / \mathrm{TP}+\mathrm{FN}$

${ }^{\mathrm{b}}$ Specificity $=\mathrm{TN} / \mathrm{TN}+\mathrm{FP}$

"The results of $2 \mathrm{mCIM}$ tests were interpreted as "indeterminate" (pinpoint colonies were present within a 16- to 18-mm zone)

${ }^{\mathrm{d}}$ Isolates with $b / a_{\mathrm{NDM}} / b / a_{\mathrm{OXA}-48}$ were defined as metallo-carbapenemase positive

$T P$ true positive, $F N$ false negative 
including $2 \mathrm{E}$. coli isolates having both $b l a_{\mathrm{NDM}}$ and $b l a_{\mathrm{OXA}-48}$, and $1 \mathrm{~K}$. pneumoniae having bla $_{\mathrm{IMP}}$. One out of 77 isolates characterized to carry the serine carbapenemase genes showed positive results by eCIM (Table $3)$. The sensitivity of the eCIM observed in this study was $89.3 \%(25 / 28)$ and the specificity was $98.7 \%(76 / 77)$ as compared to the genotype (Table 3 ).

$\mathrm{mCIM} / \mathrm{eCIM}$ assay is designed to simultaneously detect and distinguish the types of carbapenemase. Sfeir et al. showed that the sensitivity and specificity of eCIM was both $100 \%$, in the presence of $5 \mathrm{mM}$ EDTA [21]. Our results showed that the sensitivity and specificity for the $\mathrm{mCIM} / \mathrm{eCIM}$ to detect MBLs is 89.3 and $98.7 \%$, respectively (Table 3). K. pneumoniae isolate 456, an IMP8 producer, showed a false-negative result by mCIM/ eCIM (Table 4). Our sequencing data identified a wildtype $b l a_{\text {IMP-8 }}$ in isolate 456 . However, isolate 456 showed low resistance to carbapenems (Table 4). Minimum inhibitory concentrations (MICs) of isolate 456 to imipenem, ertapenem, and meropenem were $0.5,2$, and $\leq$ 0.25 , respectively (Table 4). E. coli isolates 488 and 492 containing $b l a_{\mathrm{OXA}-48} / b l a_{\mathrm{NDM}-5}$ also showed falsenegative results by $\mathrm{mCIM} / \mathrm{eCIM}$ (Table 4).

\section{Discussion}

The first CLSI recommended growth-based carbapenemase detection test was the MHT in 2009. Here, we showed that MHT had excellent sensitivity for the detection of $b l a_{\mathrm{OXA}-48}(95.1 \%)$ and bla $_{\mathrm{KPC}}(100 \%)$ (nonmetallo-carbapenemase genes) (Table 1). However, the MHT has some limitations, notably insensitivity for the detection of MBL enzymes [22]. Our results (Table 1) are consistent with previous studies which showed a high rate of false-negative MHT results with MBLproducers $[19,23,24]$. Moreover, MHT results are often difficult to interpret, and false-positive results are observed for isolates producing ESBL or AmpC $\beta$ lactamase with porin loss [25].

The overall sensitivity and specificity of MHT in this study for the detection of CPE was 84.8 and $97.8 \%$, respectively (Table 1 ). However, 16 isolates with a falsenegative result on MHT were mCIM positive (Table 2). Our results showed that the sensitivity of $\mathrm{mCIM}$ to detect MBLs is $100 \%$ and the mCIM is more accurate compared to MHT. mCIM/eCIM assay is designed to simultaneously detect and distinguish the different types of carbapenemase. Previous studies showed that the sensitivity and specificity of eCIM was both $100 \%$, in the presence of $5 \mathrm{mM}$ EDTA [21]. However, the number of $E$. coli and $K$. pneumoniae isolates used to evaluate $\mathrm{mCIM} / \mathrm{eCIM}$ assay for identifying CPE in Sfeir's report was limited [21]. In this study, 50 E. coli (32 carbapenemase producers) and $118 \mathrm{~K}$. pneumoniae (64 carbapenemase producers) were enrolled to evaluate $\mathrm{mCIM} / \mathrm{eCIM}$ for detecting CPE. Our results showed that the sensitivity and specificity for the $\mathrm{mCIM} / \mathrm{eCIM}$ to detect MBLs is 89.3 and $98.7 \%$, respectively (Table 3 ). Therefore, the inconsistency of sensitivity and specificity for the $\mathrm{mCIM} / \mathrm{eCIM}$ assay to detect MBLs between our results and Sfeir's findings might be caused by the number of tested isolates. In this study, we used PCR targeting carbapenemase genes as the gold standard to evaluate the performance of phenotypic tests for identifying carbapenemase producers. This might be a limitation as new or truncated carbapenemase genes might not be identified consistently with the phenotype.

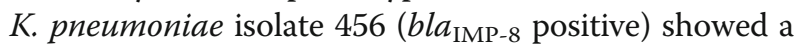
false-negative result by mCIM/eCIM (Table 4). Although wild-type $b l a_{\mathrm{IMP}-8}$ was identified in isolate 456 , the expression level of $b l a_{\text {IMP-8 }}$ in isolate 456 remains to be determined. Isolate 456 showed low resistance to carbapenems (Table 4). In addition, no additional carbapenemase genes $\left(b l a_{\mathrm{GES}}, b l a_{\mathrm{IMI}}, b l a_{\mathrm{SME}}, b l a_{\mathrm{SPM}}, b l a_{\mathrm{SIM}}\right.$, $b l a_{\mathrm{DIM}}$, and $\left.b l a_{\mathrm{GIM}}\right)$ were detected in isolate 456 . Therefore, it is worth investigating whether the carbapenem resistance level of bacteria is associated with the accuracy of $\mathrm{mCIM} / \mathrm{eCIM}$ to detect carbapenemase. E. coli isolates 488 and 492 having $b l a_{\mathrm{OXA}-48} / b l a_{\mathrm{NDM}-5}$ showed false-negative results for MBL detection by $\mathrm{mCIM} / \mathrm{eCIM}$ (Table 4). These results suggest the expression of both

Table 4 Characteristics of isolates with false mCIM/eCIM results

\begin{tabular}{|c|c|c|c|c|c|c|c|c|c|c|c|c|}
\hline \multirow[t]{2}{*}{ Isolate $^{a}$} & \multirow[t]{2}{*}{ Carbapenemase } & \multicolumn{3}{|c|}{ MIC $(\mu \mathrm{g} / \mathrm{ml})$} & \multicolumn{6}{|c|}{ Disc zone $(\mathrm{mm})$} & \multicolumn{2}{|c|}{ Phenotypic detection } \\
\hline & & $\overline{\text { IPM }}$ & ETP & MEM & IPM & ETP & MEM & DOP & $\mathrm{mCIM}$ & eCIM & $\overline{\mathrm{MHT}}$ & $\mathrm{mCIM} / \mathrm{eCIM}^{\mathrm{a}}$ \\
\hline \multicolumn{13}{|l|}{ False-positive } \\
\hline E. coli 514 & $b / a_{\mathrm{OXA}-48}$ & 8 & $\geq 8$ & $\geq 16$ & 16 & 12 & 15 & 16 & 6 & 23 & - & + \\
\hline \multicolumn{13}{|l|}{ False-negative } \\
\hline K. pneumoniae 456 & $b / a_{\mid M P-8}$ & 0.5 & 2 & $\leq 0.25$ & 22 & 18 & 25 & 25 & 19 & 20 & - & - \\
\hline E. coli 488 & $b / a_{\mathrm{OXA}-48} / b / a_{\mathrm{NDM}-5}$ & $\geq 16$ & $\geq 8$ & 8 & 6 & 6 & 6 & 6 & 6 & 6 & + & - \\
\hline E. coli 492 & $b l a_{\mathrm{OXA}-48} / b a_{\mathrm{NDM}-5}$ & $\geq 16$ & $\geq 8$ & $\geq 16$ & 6 & 6 & 6 & 6 & 6 & 6 & + & - \\
\hline
\end{tabular}

${ }^{a} \mathrm{An}$ isolate is positive for metallo-carbapenemase production when the eCIM zone size increases by $\geq 5 \mathrm{~mm}$ compared to the zone size observed for the $\mathrm{mCIM}$ and is considered negative for a metallo-carbapenemase if the increase in zone size is $<4 \mathrm{~mm}$

IPM imipenem, ETP ertapenem, MEM meropenem 
carbapenemase genes can cause the misidentification of MBLs by mCIM/eCIM. E. coli isolate 514, which carried only the serine carbapenemase genes (bla $\left.a_{\text {OXA-48 }}\right)$, showed false-positive results by eCIM based on the PCR targeting carbapenemase genes as the gold standard in this study (Table 4). However, we could not rule out the possibility of a novel carbapenemase gene in isolate 514, and therefore, an entire genome analysis of isolate 514 is worth investigating in the future.

\section{Conclusion}

Understanding the mechanism(s) causing carbapenem resistance of Enterobacteriaceae has important clinical implications and results in different prevention measurements and individualized antibiotic therapy. In this study, our results indicate that the phenotypic detection, mCIM combined with eCIM, showed high sensitivity and specificity to detect carbapenemase-producing Enterobacteriaceae, compared with MHT.

\section{Methods}

Identification of carbapenem-resistant Enterobacteriaceae isolates

Enterobacteriaceae isolates were recovered in En Chu Kong hospital, 2011 to 2019. These isolates were identified in the clinical laboratory by colony morphology, Gram stain, biochemical tests, and the Vitek 2 system (bioMérieux, Marcy l'Etoile, France) according to the manufacturer's recommendations. Susceptibility to thirdgeneration cephalosporins (ceftazidime or ceftriaxone, $30 \mu \mathrm{g} /$ disc, BD BBL ${ }^{\mathrm{mi}}$ Sensi-Disc ${ }^{\mathrm{Tm}}$, Sparks, MD, USA) for Enterobacteriaceae isolates were determined by the disk diffusion method on Mueller-Hinton ( $\mathrm{MH}$ ) agar plates (Bio-Rad, Marne la Coquette, France) based on the CLSI guidelines (M100-S30) [26]. Third-generation cephalosporin -resistant isolates were further tested for their susceptibility to carbapenems, including imipenem, ertapenem, meropenem, and doripenem $(10 \mu \mathrm{g} /$ disc, $\mathrm{BD} \mathrm{BBL}^{\mathrm{mm}}$, USA). MICs to imipenem, ertapenem, and meropenem were further determined by Vitek 2 using the AST-N322 card according to the manufacturer's instructions. A total of 419 CRE isolates were identified and stored at $-80^{\circ} \mathrm{C}$ in tryptic soy broth (TSB) containing $20 \%$ glycerol (v/v) until used.

\section{Carbapenemase gene detection}

Bacterial genomic DNA was isolated from bacteria grown overnight at $37^{\circ} \mathrm{C}$ in $3 \mathrm{~mL} \mathrm{LB}$ broth. Bacterial culture was centrifuged for $1 \mathrm{~min}$ at 12,000 rpm, and the supernatant was removed. Crude DNA extracts were obtained by suspending the pellet in $300 \mu \mathrm{L}$ distilled water and boiling at $95^{\circ} \mathrm{C}$ for $10 \mathrm{~min}$, followed by centrifugation at $12,000 \mathrm{rpm}$ for $5 \mathrm{~min}$. The supernatant containing
DNA was transferred to a new eppendorf tube, and the DNA samples were stored at $4{ }^{\circ} \mathrm{C}$ until testing.

PCR targeting carbapenemase genes was used as the standard to assess the performance of phenotypic tests. Therefore, PCR amplification for the detection of $\beta$ lactamase genes $\left(b l a_{\mathrm{KPC}}, b l a_{\mathrm{NDM}}, b l a_{\mathrm{IMP}}, b l a_{\mathrm{VIM}}, b l a_{\mathrm{OXA}-48 \text {, }}\right.$ bla $_{\mathrm{GES}}, b l a_{\mathrm{IMI}}, b l a_{\mathrm{SME}}, b l a_{\mathrm{SPM}}, b l a_{\mathrm{SIM}}, b l a_{\mathrm{DIM}}$, and $\left.b l a_{\mathrm{GIM}}\right)$ was carried out on a iCycler iQ5 real time PCR system (Bio-Rad, USA) with the HotStar PCR SuperMix (GeneDireX, USA). Primers and PCR procedures used in $\beta$ lactamase genes detection were described in previous studies [15, 27-29]. The PCR products were analyzed by electrophoresis with $2 \%$ agarose gels in $0.5 \times$ Tris-borateEDTA (TBE) buffer. The gels were stained with Novel Juice (GeneDireX, USA), and the PCR products were visualized with UV light. Clinical K. pneumoniae isolates harboring $b l a_{\mathrm{KPC}}, b l a_{\mathrm{NDM}}, b l a_{\mathrm{IMP}}, b l a_{\mathrm{VIM}}$, and $b l a_{\mathrm{OXA}-48}$ were used as PCR positive controls. In accessibility to have strains with bla $a_{\mathrm{GES}}, b l a_{\mathrm{IMI}}, b l a_{\mathrm{SME}}, b l a_{\mathrm{SPM}}, b l a_{\mathrm{SIM}}, b l a_{\mathrm{DIM}}$, or $b l a_{\mathrm{GIM}}$ as our PCR controls. The PCR products with relevant expected size were purified and verified by sequencing.

\section{Phenotypic detection of carbapenemase-producing Enterobacteriaceae}

MHT, mCIM, and eCIM were performed on CRE isolates according to the CLSI guidelines to detect the presence of carbapenemase [20]. The mCIM and eCIM procedures are illustrated in Fig. 1a. In brief, a $1-\mu \mathrm{L}$ loopful of bacteria was resuspended in a $2-\mathrm{mL}$ tube of TSB. Another 1- $\mu \mathrm{L}$ loopful of bacteria was resuspended in a 2-mL tube of TSB supplemented with EDTA (Thermo Fisher Scientific, Carlsbad, CA, USA) at a final concentration of $5 \mathrm{mM}$ (add $20 \mu \mathrm{L}$ of $0.5 \mathrm{M}$ EDTA to 2 $\mathrm{mL}$ of TSB). A meropenem disk was placed in each tube, and the tubes were incubated at $35^{\circ} \mathrm{C}$ for $4 \mathrm{~h} \pm 15 \mathrm{~min}$. Subsequently, the disks were removed and applied to $\mathrm{MH}$ agar plates freshly plated with a $0.5 \mathrm{McF}$ arland suspension of a carbapenem-susceptible $E$. coli ATCC 25922 strain (Fig. 1a). The plates were incubated at $35^{\circ} \mathrm{C}$ for 16 to $20 \mathrm{~h}$ and the mCIM and eCIM results were interpreted as previously described $[21,30]$. The $\mathrm{mCIM}$ is considered negative if the zone size is $\geq 19 \mathrm{~mm}$, positive if the zone size is 6 to $15 \mathrm{~mm}$, or intermediate (defined as positive) if pinpoint colonies are present within a 16- to $18-\mathrm{mm}$ zone $[21,30]$. An isolate is positive for metallo-carbapenemase production when the eCIM zone size increases by $\geq 5 \mathrm{~mm}$ compared to the zone size observed for the $\mathrm{mCIM}$ and is considered negative for a metallo-carbapenemase if the increase in zone size is $<4 \mathrm{~mm}[21,30]$. According to CLSI guidelines [20], K. pneumoniae ATCC BAA-1706 (carbapenemase negative), $K$. pneumoniae ATCC BAA-1705 (bla $a_{\mathrm{KPC}}$ positive), and K. pneumoniae ATCC BAA-2146 (bla $a_{\mathrm{NDM}}$ positive) were used as internal controls for 
mCIM and eCIM tests. The MHT, mCIM and eCIM tests were replicated by two independent investigators to ensure reproducibility.

\section{Abbreviations}

CLSI: Clinical \& Laboratory Standards Institute; CPE: Carbapenemaseproducing Enterobacteriaceae; CRE: Carbapenemase-resistant Enterobacteriaceae; DOP: Doripenem; eCIM: EDTA carbapenem inactivation method; ETP: Ertapenem; FN: False negative; FP: False positive; IPM: Imipenem; MBL: Metallo- $\beta$-lactamases; MEM: Meropenem; mCIM: Modified carbapenem inactivation method; MHT: Modified Hodge test; MIC: Minimum inhibitory concentration; TN: True negative; TP: True positive

\section{Acknowledgements}

The authors thank Adam Schaenzer of McMaster University for his thoughtful comments and efforts towards improving our manuscript.

\section{Authors' contributions}

YMT, SW, and HCC were responsible for the study design and the interpretation of results of bacterial identification, antibiotic susceptibility tests, and phenotypic detection of carbapenemases. CYK and LLW were responsible for manuscript preparation. All authors read and approved the final manuscript. YMT and SW contributed equally to this paper (co-first authors). CYK and LLW contributed equally to this paper (co-corresponding authors).

\section{Funding}

This work was supported by the Ministry of Science and Technology, Taiwan (grant numbers MOST 108-2911-I-010-508 and 109-2320-B-010-036-MY3); and the En Chu Kong hospital, Taiwan (grant number ECKH_W10901).

\section{Availability of data and materials}

All data generated or analyzed during this study are included in this published article.

\section{Ethics approval and consent to participate}

Not applicable.

\section{Consent for publication}

Not applicable.

\section{Competing interests}

All authors have no conflicts of interest to declare.

Received: 13 May 2020 Accepted: 12 October 2020

Published online: 17 October 2020

\section{References}

1. Wang Q, Zhang Y, Yao X, Xian H, Liu Y, Li H, et al. Risk factors and clinical outcomes for carbapenem-resistant Enterobacteriaceae nosocomial infections. Eur J Clin Microbiol Infect Dis. 2016;35(10):1679-89.

2. Iredell J, Brown J, Tagg K. Antibiotic resistance in Enterobacteriaceae: mechanisms and clinical implications. BMJ. 2016;352:h6420.

3. Barry AL, Jones RN, Thornsberry C, Ayers LW, Kundargi R. Imipenem (Nformimidoyl thienamycin): in vitro antimicrobial activity and beta-lactamase stability. Diagn Microbiol Infect Dis. 1985;3(2):93-104.

4. Sheu CC, Chang YT, Lin SY, Chen YH, Hsueh PR. Infections caused by Carbapenem-resistant Enterobacteriaceae: an update on therapeutic options. Front Microbiol. 2019;10:80.

5. Suay-Garcia B, Perez-Gracia MT. Present and Future of Carbapenem-resistant Enterobacteriaceae (CRE) Infections. Antibiotics (Basel). 2019;8(3):122.

6. Sugawara E, Kojima S, Nikaido H. Klebsiella pneumoniae Major Porins OmpK35 and OmpK36 allow more efficient diffusion of beta-lactams than their Escherichia coli homologs OmpF and OmpC. J Bacteriol. 2016;198(23): $3200-8$

7. Ye Y, Xu L, Han Y, Chen Z, Liu C, Ming L. Mechanism for carbapenem resistance of clinical Enterobacteriaceae isolates. Exp Ther Med. 2018;15(1): $1143-9$.

8. Kopotsa K, Osei Sekyere J, Mbelle NM. Plasmid evolution in carbapenemaseproducing Enterobacteriaceae: a review. Ann N Y Acad Sci. 2019;1457(1):61-91.
9. Ambler RP. The structure of beta-lactamases. Philos Trans R Soc Lond Ser B Biol Sci. 1980:289(1036):321-31.

10. Queenan AM, Bush K. Carbapenemases: the versatile beta-lactamases. Clin Microbiol Rev. 2007:20(3):440-58 table of contents.

11. Bush K, Jacoby GA. Updated functional classification of beta-lactamases. Antimicrob Agents Chemother. 2010;54(3):969-76.

12. Cohen Stuart J, Leverstein-Van Hall MA. Dutch working party on the detection of highly resistant $\mathrm{M}$, guideline for phenotypic screening and confirmation of carbapenemases in Enterobacteriaceae. Int J Antimicrob Agents. 2010;36(3):205-10

13. Chen L, Mathema B, Chavda KD, DeLeo FR, Bonomo RA, Kreiswirth BN. Carbapenemase-producing Klebsiella pneumoniae: molecular and genetic decoding. Trends Microbiol. 2014:22(12):686-96.

14. Martinez-Martinez L, Gonzalez-Lopez JJ. Carbapenemases in Enterobacteriaceae: types and molecular epidemiology. Enferm Infecc Microbiol Clin. 2014;32(Suppl 4):4-9.

15. Yigit H, Queenan AM, Anderson GJ, Domenech-Sanchez A, Biddle JW, Steward CD, et al. Novel carbapenem-hydrolyzing beta-lactamase, KPC-1, from a carbapenem-resistant strain of Klebsiella pneumoniae. Antimicrob Agents Chemother. 2001;45(4):1151-61.

16. Noval M, Banoub M, Claeys KC, Heil E. The Battle is on: new Beta-lactams for the treatment of multidrug-resistant gram-negative organisms. Curr Infect Dis Rep. 2020;22(1):1

17. Bialvaei AZ, Kafil HS, Asgharzadeh M, Yousef Memar M, Yousefi M. Current methods for the identification of carbapenemases. J Chemother. 2016;28(1):1-19.

18. Clinical \& Laboratory Standards Institute (CLSI). Performance standards for antimicrobial susceptibility testing. 19th ed; 2009. CLSI supplement M100-S28.

19. Tamma PD, Simner PJ. Phenotypic Detection of Carbapenemase-Producing Organisms from Clinical Isolates. J Clin Microbiol. 2018;56(11):e01140-18.

20. Clinical \& Laboratory Standards Institute (CLSI). Performance standards for antimicrobial susceptibility testing. 28th ed; 2018. CLSI supplement M100-S28.

21. Sfeir MM, Hayden JA, Fauntleroy KA, Mazur C, Johnson JK, Simner PJ, et al. EDTA-Modified Carbapenem Inactivation Method: a Phenotypic Method for Detecting Metallo-beta-Lactamase-Producing Enterobacteriaceae. J Clin Microbiol. 2019:57(5):e01757-18.

22. Hoang CQ, Nguyen $H D$, Vu HQ, Nguyen AT, Pham BT, Tran $T L$, et al. Emergence of New Delhi Metallo-Beta-lactamase (NDM) and Klebsiella pneumoniae Carbapenemase (KPC) production by Escherichia coli and Klebsiella pneumoniae in southern Vietnam and appropriate methods of detection: a cross-sectional study. Biomed Res Int. 2019;2019:9757625.

23. Girlich D, Poirel L, Nordmann P. Value of the modified Hodge test for detection of emerging carbapenemases in Enterobacteriaceae. J Clin Microbiol. 2012;50(2):477-9.

24. Tamma PD, Opene BN, Gluck A, Chambers KK, Carroll KC, Simner PJ. Comparison of 11 phenotypic assays for accurate detection of Carbapenemase-producing Enterobacteriaceae. J Clin Microbiol. 2017:55(4):1046-55.

25. Pasteran F, Mendez T, Rapoport M, Guerriero L, Corso A. Controlling falsepositive results obtained with the Hodge and Masuda assays for detection of class a carbapenemase in species of enterobacteriaceae by incorporating boronic acid. J Clin Microbiol. 2010;48(4):1323-32.

26. Clinical \& Laboratory Standards Institute (CLSI). Performance standards for antimicrobial susceptibility testing. 30th ed; 2020. CLSI supplement M100-S30.

27. Doyle D, Peirano G, Lascols C, Lloyd T, Church DL, Pitout JD. Laboratory detection of Enterobacteriaceae that produce carbapenemases. J Clin Microbiol. 2012:50(12):3877-80.

28. Ellington MJ, Kistler J, Livermore DM, Woodford N. Multiplex PCR for rapid detection of genes encoding acquired metallo-beta-lactamases. J Antimicrob Chemother. 2007;59(2):321-2.

29. Mlynarcik P, Roderova M, Kolar M. Primer evaluation for PCR and its application for detection of Carbapenemases in Enterobacteriaceae. Jundishapur J Microbiol. 2016;9(1):e29314

30. Pierce VM, Simner PJ, Lonsway DR, Roe-Carpenter DE, Johnson JK, Brasso WB, et al. Modified Carbapenem inactivation method for phenotypic detection of Carbapenemase production among Enterobacteriaceae. J Clin Microbiol. 2017:55(8):2321-33.

\section{Publisher's Note}

Springer Nature remains neutral with regard to jurisdictional claims in published maps and institutional affiliations. 